\title{
Shoes influence in women posture
}

\author{
Geraldo Fabiano de Souza Moraes ${ }^{\mathrm{a},{ }^{*}}$, Davidson Passos Mendes ${ }^{\mathrm{b}}$, , Adriana Antunes Papinnic \\ ${ }^{a}$ Physiotherapist, M.Sc Rehabilitation Science, Assistent Professor at University Federal of Itajubá-Campus \\ Itabira, Itabira, Minas Gerais, Brazil.E-mail: geraldofsmoraes@gmail.com \\ ${ }^{\mathrm{b}}$ Physiotherapist, M.Sc Production Engineering Assistent Professor at University Federal of Itajubá-Campus \\ Itabira, Itabira, Minas Gerais, Brazil.E-mai: davidsonpmendes@gmail.com \\ 'Physiotherapist, B.Sc Physical TherapyE-mail:dripantunes@yahoo.com.br
}

\begin{abstract}
One of the most prevalent aspects is women with complaints of discomfort in the lumbar region for the use of high heeled shoe. Authors described that there may be a relation between attitude and the present discomfort, often associated with muscular fatigue and increase the forces of reaction soil during the use of such footwear. The purpose of this study was to evaluate possible changes postural associated with the use of different types of shoes and barefoot. Fifteen sedentary women were subjected to a static evaluation posture with the use of the software SAPO. Analysis of variance (ANOVA) repeated measures was used to investigate differences between the shoes in all variables postural analyzed. The results showed no significant difference in static position with the types of shoes and barefoot. It was concluded that the shoes did not interfere in static position.
\end{abstract}

Keywords: Ergonomics, shoes, posture occupational risk, work process

\section{Introduction}

According Esenyel et al. [1], 37\% to $69 \%$ of women wearing high heels on a day-to-day, which can, in some cases, lead to decreased function of the lower limbs (LL), and impacts, gait disorder [2].

In relation to the onset of disability - which is characterized as the result of a relationship between the state or condition of health of the individual and the circumstances in which the individual lives [3] -, there are several reports related to the type of shoe used, the task performed and the context involved [4]. One of the most prevalent complaints of women with lower back discomfort while wearing high heels [4]. Snow and Williams [5] reported that there may be a relationship between the attitude of present and discomfort usually associated with muscle fatigue and increased ground reaction forces when using this type of footwear.

There is a controversy in the literature about the effect of the use of high heels on postural changes and overload on the spine and body segments. Snow and Williams [5] reported that there was no significant difference in the average between the curvature in the lumbar or pelvic tilt and the height of the jump.

Opila et al. [6] demonstrated that the use of high heels, compared with the barefoot condition, causes a straightening of the lumbar region. One explanation for this would be a shortening of the isometric contraction of the posterior chain which generates a correction of the lumbar spine and the system attempts to compensate for the anterior tilt of the trunk that is associated with the use of high-heeled shoes. Another factor to consider is that in order to reposition the center of gravity of the body posteriorly and relieve the sensation of falling forward, is a co-contraction of abdominal and paraspinal muscles.

Lateur et al. [7] reported that the use of high heels causes a decrease in lumbar curvature. This can be explained by the individual's center of gravity does not change significantly when it is with high heels or low heels, which may indicate the existence of an

\footnotetext{
* Corresponding author. University of Itajubá UNIFEI. Curso de Engenharia de Saúde e Segurança. Rua Um s/nº Distrito Industrial. Itabira. Minas Gerais. Brasil. CEP 35903-081. E-mail: geraldmoraes@terra.com.br
} 
anatomical compensation in the lower limbs and lumbar spine to keep the body in balance.

The use of high heels in orthostatic posture implies pelvic retroversion, bringing the knees and ankles in relation to the gravity line, posterior displacement of the head and thoracic spine. The use of high heels submits excessive torque to the knee, especially in varus, which makes the medial portion of this joint is more susceptible to degenerative changes of the articular cartilage, and thus be related to a higher incidence of osteoarthritis [8].

Kerrigan, Todd and Riley [9] studied the influence of thick and thin heels and concluded that walk with high heels increase strength through the patellofemoral joint and compression in the medial compartment of the knee and Kerrigan, and Karvosky Lelas [10] described that thick heels and cause abnormal forces on the medial compartment of the knee, which may predispose to degenerative changes of the knees.

The use of high heels, the body undergoes through a non-physiological conditions that require constant adjustments and accommodations. The function of the joints is changed, which can unleash forces and torques exerted above the normal. Further, it requires that postural changes are made to maintain postural balance [11].

Frey et al. [12] found that $75 \%$ of women using high heel had one or more deformities in the forefoot, and hallux valgus $71 \%, 50 \%$ hammer toes, bunions $18 \%$ of the metatarsal $\mathrm{V}, 13 \%$ prominence of the metatarsal head and $4 \%$ had multiple deformities.

Among the best resources for prevention is lower opt for shoes that give greater support and balance, and do not stress certain areas of the body. The most recommended by doctors is to do during the week, rotate between jumps, not letting your feet get used to a specific type of jump. Another good practice is to regularly stretch the muscles of the thigh and calf [13].

In recent years, work-related musculoskeletal disorders (MSDs) and workplace accidents have worried business leaders and officials, mainly due to absenteeism, decreased productivity and loss of income. Professionals affected by these problems need to keep away from his professional activities for a certain period. MSDs are problems that can occur when a person uses a certain other body part, or mobilizing repeating gestures, which causes a local pain in the joints [14].

Today, women are more embedded in the labor market and the frequent use of jump is primarily associated with aesthetics. Little has been studied about the influence of footwear on lower limb joints and posture. Due to reports of discomfort such as pain, postural changes and deformities in the feet, it is extremely important to check what kind of footwear would be the most appropriate and comfortable for everyday use.

\subsection{Objective}

The aim of this study was to assess possible static postural changes associated with the use of different types of footwear and barefoot.

\section{Methodology}

\subsection{Study Design and Sample}

It is a cross-sectional observational study, which was used a convenience sample of 15 young women aged between 18 and 35 years, sedentary. Exclusion criteria were women who owned joint stiffness, pain that disables the tests, lower limb discrepancy (up to one centimeter), ankle sprains have been less than six months, were diagnosed with ankle ligament rupture, they undergone surgery or physical therapy in the lower limbs less than six months. Obese - BMI $\geq 30$ [15], pregnant, diabetic, who used walking aids and / or soles, edema of ankles and feet, two inches above atrophy of calf and thigh. Possessing hallux valgus, bunions, and metatarsal $\mathrm{V}$ of Morton's neuroma preventing the holding of the proceedings. This study was approved by the Ethics and Research of Newton Paiva University Center on the advice number 0082 of $06 / 03 / 2008$.

\subsection{Postural Assessment Instrument}

Program was used for Posture Evaluation Software - Software for Postural Assessment (SAPO, Incubator FAPESP, SP, Brazil). It is a computer program that, from scanned photographs of the individual, allows the measurement of the position, length, angle and alignment, among other properties, of an individual body segments, allowing a postural analysis in static frontal (seen anterior and posterior) and sagittal (right eye and left)

\subsection{Procedures}

All subjects were informed about the objectives and procedures of the study and then signed a consent form. Then, there was a standardized evaluation by a properly trained examiner for identification, medical history and physical examination of each 
subject. On physical examination was performed goniometry dorsiflexion bilaterally.

Later we performed the registration of voluntary static posture of standing, in the frontal (front and back views) and sagittal (right and left) by Cybreshot Sony digital camera model DSC-P200 (Sony Electronics, Inc. (C), San Diego, CA), the following order of shoes: barefoot, slippers, heels, high heels and sneakers. The photos were stored for later analysis in the SAPO.

The shoes used were high-heeled Chanel type , jump down like chanel, tennis, slippers and barefoot. We considered those high-heeled shoe with height from nine to eleven inches and one to jump down from five to seven centimeters. For tennis was necessary that it had a high heel from two to four centimeters.

\subsection{Data reduction}

To evaluate the static posture, we used the program and SAPO variables were: horizontal alignment of the head (AHC), vertical alignment of the head (AVCA), vertical alignment of the trunk (AVT), hip angle (AQ), alignment vertical body (AVCO), horizontal alignment of the pelvis (AHP), knee angle (AJ), ankle angle (TA), center of gravity: the frontal asymmetry (APF), and asymmetry in the sagittal plane (APS). All values corresponding to the variables analyzed were obtained following the recommendations of the program for analysis of posture in the conditions studied.

\subsection{Statistical Analysis}

Analysis of Variance (ANOVA) repeated measures was used to investigate differences statistically significant between the shoes in all variables of SAPO.

\section{Results}

\subsection{Sample Characterization}

The study included 15 volunteers aged between 18 to 31 years $(23.2 \pm 3.36$ years $)$, sedentary. The usage time of the shoes / week is shown in Fig.3. The change in the use of shoes in hours / days is shown in Fig.4. The residence time in the standing position in hours / days is shown in Fig.5. The number of the shoes ranged from 36 to $37(36 \pm 0.81)$. Of the fifteen volunteers, thirteen were right-handed and two were sinister.

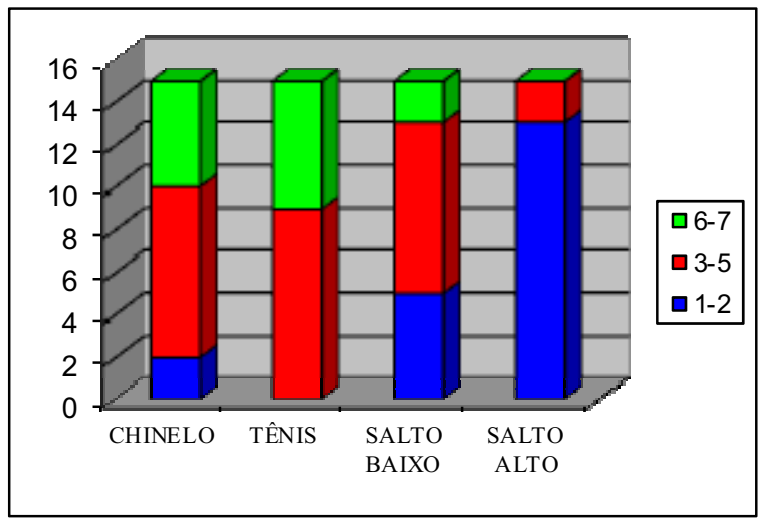

Figure 1: Period of shoes wearing/week

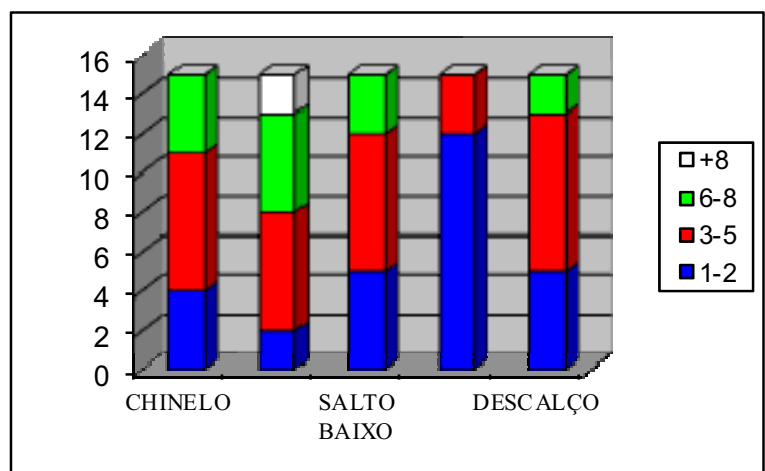

Figure 2: Variation in the shoes wearing in hours/day

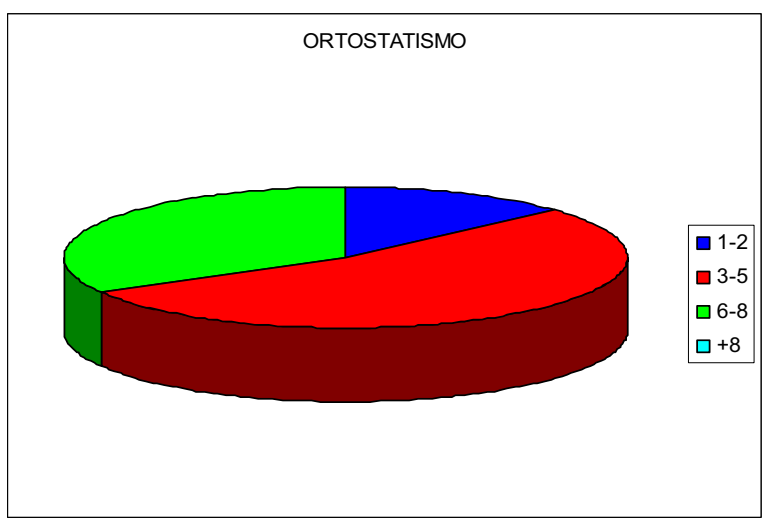

Figure 3: Permanence time in the orthostatic position in hours/day 


\subsection{Postural Assessment}

For using SAPO postural assessment was not presented significant difference for all variables evaluated in the right and left lateral view: $\operatorname{AHCD}(\mathrm{p}=$ $0.822), \operatorname{HAEC}(p=0.651), \operatorname{AVCAD}(p=0.713)$, $\operatorname{AVCAE}(\mathrm{p}=0.998) \operatorname{AVTD}(\mathrm{p}=0.785), \operatorname{AVTE}(\mathrm{p}=$ $0.387)$, AQD $(\mathrm{p}=0.846)$, AQD $(\mathrm{p}=0.489)$, AVCOD $(p=0.059), \operatorname{AVCO}(p=0.076), \operatorname{AHPD}(p=0.909)$, $\operatorname{AHPE}(p=0.906), \operatorname{AJD}(p=0.722), \operatorname{AJE}(p=0.390)$, ATD $(p=0.399)$, ATE $(p=0.453)$. For the variables related to the center of gravity no significant differences: APF $(p=0.291)$ and APS $(p=0.339)$.

\section{Discussion}

Posture can be considered the position taken by the body segments during activities of daily living (ADL) performed by an individual [16]. A proper posture can be considered one in which the body is in favorable condition for carrying out the task [17].

Studies have described the influence of high heels in the adaptation of locomotion of individuals $[12,18]$. During the dynamic analysis of locomotion, several modifications are necessary to accommodate the apparatus of the individual conditions that the system is being subjected, as well as the influences of the context in which the task is being performed $[19,20]$.

In this study, the evaluation of static posture with different shoes and barefoot condition was not observed significant differences for all variables. In static posture, most adaptations do not correspond to those observed in posture during dynamic activities [21]. This fact can be explained by changes in demand-capacity ratio associated with the conditions in which the activity is taking place.

There are several factors that may interfere with the body alignment and positioning of body segments, such as muscular efficiency and pathological conditions of neurological or musculoskeletal conditions present in the usual routine or adverse.

Thus, one of the factors that can be highlighted as a direct influence on the static and dynamic posture are adaptations musculoskeletal conditions resulting from performing a certain task, and the compensation arising from same.

Regarding the use of shoes, the muscles of the lower limbs can be shortened, especially the posterior chain muscles as triceps sural, sural buttock, paravertebral.

The volunteers were in the habit of using more negative heel shoes and high heels than barefoot dur- ing the week and spend hours with them. Thus, short periods of wearing shoes with the heel significantly, some may have affected the attitude of the volunteers during the tests.

Women who have a habit of wearing high heels regularly, such as secretaries, long periods and remain standing, as clerks, tend to develop adaptive shortening the condition of wearing shoes that situation and keep the body in ADLs and professional activities [22]. Some women report difficulties during locomotion by the presence of pain, especially in the ankles and distort when they move from highheeled shoes to shoes with lower slope [23].

Regarding the assessment of the center of gravity, through the APF and APS variables, there were no differences regarding the conditions of footwear and barefoot. Lateur et al. [7] demonstrated that the use of high-heeled shoes and did not change significantly down the center of gravity of the volunteers evaluated. Due to anatomical and anthropometric women, such as enlargement of the pelvis, changes in body composition and quadriceps angle, the compensation system often develops in the lower limbs and lumbar region.

Another factor reported in the literature is the condition of laboratory evaluation, in which the volunteer is aware of the activities to be performed mainly during the assessment and recording in static posture [24].

In clinical practice can be observed frequently reported pain in the lower back, hips, knees and ankles. The sporadic use of high heels can be considered a disorder in which the individual will need to find strategies for the adaptive system can support the weight body with a muscular lower demand and consequently lower energy expenditure. The inability of the system to adapt to new conditions may be a relevant factor for the development of painful picture and incidence of injuries in the joints of lower limbs, as well as the acceleration of the degenerative joint.

Casarin [25] in their study with 14 women with daily use of high heels and 10 non-daily use with high heels, and analyzed changes in postural EMG activity in a static manner, in the standing position of the gastrocnemius and erector spinae barefoot conditions, heel, low heels and high heels, found no significant difference in lumbar angle of all volunteers evaluated.

Women of different occupations are exposed to health hazards associated with the use of high-heeled shoes. Biomechanical changes in gait, posture, at the request of the muscles, and muscle balance, are some aspects that can trigger a process of occupational 
illness. Risks of accidents and incidents can be accentuated when the use of inappropriate shoes, sum up the activity to be developed, the stance taken, as well as the environmental conditions of work. Therefore, preventive measures and ergonomics should be adopted from an organizational analysis should be seen as an investment and not as an expense for a company.

\subsection{Clinical relevance}

There is in the literature a great deal of information about the assessment associated with postural assessment of lower limb muscle activity and lumbar spine with the use of different shoes and barefoot. In addition, there is controversy in some studies, especially regarding those that simulate the elevation of the heel, gradually, with the apparatus of wood and other materials.

Regular use of jump, especially the high, can lead to motor learning of woman who wears this shoe with greater frequency as the repetition of a task is a determining factor for cortical plasticity which, in turn, automatically generates the gesture (30).

Such factors listed don't have a direct association, but it may be noted that the shoes are factors to be considered adaptive in the conditions found in women who make regular use of high heels.

An ergonomic analysis is important emphasize that women need to make constant use of high-heeled shoes, such as secretaries, should be targeted for possible postural problems arising from the indiscriminate use of this tool. One should take into consideration the support base, way to go, positions taken, and the quality of the shoe and security conditions so that it does not compromise the health of the worker.

\section{Conclusion}

The use of different shoes that do not interfere with the static posture while standing upright with the use of flip-flops, sneakers, heels, high heels and barefoot condition, so the analysis of the shoe alone can't be considered as one factor in women's posture changes.

\section{References}

[1] M. Esenyel and et al., Kinetics of High-Heeled Gait, Journal of the American Podiatric Medical Association, 93 (2003), 2732.

[2] W. Hong and et al., Influence of heel height and shoe insert on comfort perception and biomechanical performance of young female adults during walking, Foot \& Ankle international, 26, (2005), 1042-1048.

[3] N. Farias and C. Buchalla, A classificação internacional de funcionalidade, incapacidade e saúde da organização mundial da saúde: conceitos, usos e perspectivas, Revista Brasileira de Epidemiologia, 8 (2005), 187-193.

[4] C. Frey, Foot Health and Shoewear for Women, Clinical Orthopaedics and Related Research, 372 (2000), 32-44.

[5] R. Snow and K. Williams, High heeled shoes: their effect on center of mass position, posture, three-dimensional kinematics, rear foot motion and ground reaction forces, Archives of Physical Medicine and Rehabilitation, 75 (1994), 568-576.

[6] K.Opila and et al. Postural alignment in barefoot and highheeled stance, Spine, 13 (1988), 542-547.

[7] B. Lateur and et al., Footwear and posture: Compensatory strategies for heel height, American Journal of Physical Medicine \& Rehabilitation, 70 (1991), 246-254.

[8] I. Sacco and et al. Análise biomecânica e cinesiológica de posturas mediante fotografia digital: estudo de casos, Revista Brasileira de Ciência e Movimento, 11 (2003), 25-33.

[9] D. Kerrigan, M. Todd, P. Riley, Knee osteoarthritis and highheeled shoes, The Lancet, 351 (1998), 1399-1401.

[10]D. Kerrigan, J. Lelas and M. Karvosky, Women's shoes and knee osteoarthritis, The Lancet, 357 (2001), 1097-1098.

[11]L. Wannmacher, Osteoartrose de joelhos Parte II: Evidências sobre abordagens não-medicamentosas, Uso racional de medicamentos: temas selecionados, 3 (2006), 1-6.

[12]C. Frey and et al., American Orthopaedic Foot and Ankle Society women's shoe survey. Foot \& Ankle, 14 (1993), 78-81.

[13]J. Potério-Filho and et al., The effect of walking with highheeled shoes on the leg venous pressure, Angiology, 57 (2006), 424-430.

[14]Congresso internacional de Ergonomia e Usabilidade de Interfaces Humano-Tecnologia: Produtos, Informação, Ambiente Construído, Transporte, 6, 2006, Bauru. Diferenças de gênero na percepção de riscos relacionados ao calçado feminino de salto alto e bico fino. Bauru: UNESP, 2006.

[15]L. Anjos, Body mass index as a tool in the nutritional assessment of adults: a review. Revista de Saúde Pública, 26 (19920.

[16] M. Young, A Review on Postural Realignment and its Muscular and Neural Components. Elite Track, 2003.

[17] J. Oliver and A. Middleditch, Anatomia funcional da coluna vertebral. Rio de Janeiro, RJ: Revinter. 1998.

[18]A. Hansen and D. Childress, Effects of shoe heel height on biologic rollover characteristics during walking. Journal of Rehabilitation Research and Development, 41 (2004), 547554.

[19] S. Oliveira, M. Santos, G. Santos, W. Monteiro, C. Oliveira and F. Fregni, Análise do Tempo de Adaptação da Marcha em Mulheres Adultas Jovens. X Encontro Latino Americano de Iniciação Científica e VI Encontro Latino Americano de PósGraduação - Universidade do Vale do Paraíba, 2006.

[20] Melo, F. Controlo postural: controlo reflexo versus controlo dinâmico. Rev Bras Educ Fís Esp, 20 (2006) 107-109.

[21]A. Bankoff, P. Ciol, C. Zamai, A. Schmidt, and D. Barros, Estudo do equilíbrio corporal postural através do sistema de baropodometria eletrônica. Conexões, 2 (2004) 87-104.

[22] De Luca, C. Low Back Pain: A Major Problem with Low Priority. J Rehabil Res Develop, 34 (1997).

[23]A. Gefen and et al. Analysis of muscular fatigue and foot stability during high-heeled gait. Gait and Posture, 15 (2002), 56-63.

[24]I. Stokes, P. Allard, and J. Blachi, Three Dimensional Analysis of Human Moviment. Champaign: Human Kinetics Publishers, 1995. 
[25]C. Casarin, A influência do calçado de salto alto sobre a lordose lombar associada aos músculos lombares $e$ gastrocnêmio. 2005. 49 f. Dissertação (Mestrado) -
Universidade Estadual de Campinas, Faculdade de Odontologia de Piracicaba. 2005. 